\title{
Ensino Remoto: O que Pensam os Alunos e Professores?
}

\author{
Murilo Carvalho Feitosa ${ }^{1}$, Patrícia de Souza Moura ${ }^{2}$, Maria do Socorro Ferreira \\ Ramos $^{3}$, Otávio Paulino Lavor ${ }^{4}$ \\ ${ }^{1}$ Curso de Graduação em Engenharia Elétrica - Universidade Federal Rural do Semi- \\ árido (UFERSA) \\ Pau dos Ferros - RN - Brasil \\ ${ }^{2}$ Programa de Pós-Graduação em Ensino (PPGE) - Universidade do Estado do Rio \\ Grande do Norte (UERN) \\ Pau dos Ferros - RN - Brasil \\ ${ }^{3}$ Programa de Pós-Graduação em Ensino (PPGE) - Universidade do Estado do Rio \\ Grande do Norte (UERN) \\ Pau dos Ferros - RN - Brasil \\ ${ }^{4}$ Departamento de Ciências Exatas e Naturais - Universidade Federal Rural do Semi- \\ árido (UFERSA) \\ Pau dos Ferros - RN - Brasil \\ murilocfeitosalgmail.com, patryciacedrolgmail.com, \\ mariasframosegmail.com, otavio.lavoreufersa.edu.br
}

\begin{abstract}
In times of social detachment, remote teaching has become a possibility for teaching and learning. This modality provides for synchronous and asynchronous activities without face-to-face contact, in which several technologies can be used. At this point, it can be questioned how teachers and students view remote teaching as regards difficulties and opportunities. In order to know the opinion of those involved, a semi-structured interview is conducted with ten students and six teachers from different courses, areas and levels of education. The comments point to the difficulties of interaction and infrastructure, well as opportunities to experience new technologies and new environments of teaching and learning.
\end{abstract}

Resumo. Em tempos de distanciamento social, o ensino remoto se tornou uma possibilidade para ensinar e aprender. Essa modalidade prevê atividades síncronas e assíncronas sem o contato presencial, em que podem ser utilizadas diversas tecnologias. Neste momento, pode ser questionado como os professores e alunos vêem o ensino remoto quanto às dificuldades e oportunidades. A fim de conhecer a opinião dos envolvidos, uma entrevista semiestruturada é feita com dez alunos e seis professores de diversos cursos, áreas e níveis de ensino. Os comentários apontam para as dificuldades de interação e infraestrutura, bem como oportunidades para vivenciar as novas tecnologias e novos ambientes de ensino e aprendizagem. 


\section{Introdução}

Segundo Rodrigues Júnior e Véras (2019), migrou-se do ambiente educativo presencial para o virtual, tornando o aluno um ser ativo e corresponsável por sua aprendizagem. Nesse sentido, o ensino remoto tem sido uma possiblidade para as instituições oferecerem as suas aulas sem o contato presencial nessa época de isolamento social. Essa modalidade considera o uso de Tecnologias de Informação e Comunicação para realizar atividades síncronas que tem exemplo as reuniões em plataformas específicas e assíncronas que tem como exemplo uso de mensagens e envio de videoaulas.

Segundo Hitzschky et al (2019), existe atualmente uma preocupação contemporânea em inserir as TICs nas práticas pedagógicas, para atender as demandas de comunicabilidade, conhecimento e formação profissional. Nesse sentido, é possível compreender que TICs podem ser um fator para o desenvolvimento do pensamento científico, crítico e social.

Quanto às oportunidades proporcionadas pelas TICs, pode-se dizer:

[...]as TICS permitem profundas mudanças no âmbito educacional, mas também sociais e econômicas, possibilitando a expansão de nossas fontes intelectuais/acadêmicas. A Internet surge como facilitadora de informações, gerando diferentes ferramentas e expandindo as escolhas dos sujeitos, que se associam por meio de seus gostos e interesses. [Mourão, Araújo e Silva, 2019, p. 11]

As tecnologias são aliadas ao processo de ensino e aprendizagem, mas deve-se destacar as dificuldades e desafios enfrentados pelos envolvidos. Charnei (2019) afirma que é possível usar a tecnologia nas atividades escolares, mas é necessário que o professor esteja aberto a novas possibilidades de ensino e aprendizagem.

Sair de um ensino presencial movido por uma interação física entre público e infraestrutura física disponível e submeter-se ao ensino remoto é um desafio para alunos e professores. Neste contexto, Melo e Maia (2019) destacam que é importante que os professores estejam cientes das possibilidades de que podem se servir com o uso das tecnologias digitais. Assim, compreende-se que as TICs podem agregar valores motivacionais a qualquer modalidade de ensino.

As tecnologias da informática que integram a rede mundial de computadores, com ilimitadas formas de produção de conhecimentos colocam-nos diante de experiências que auxiliam o desenvolvimento da nossa inteligência. Consequentemente viabilizam uma formação essencial para lidar com os avanços tecnológicos de hoje. [Pimentel e Nicolau, 2018, p.45]

Mesmo compreendendo que as TICs proporcionam mecanismos para ensinar e aprender, Pimentel e Nicolau (2018) destacam que se o público não tem acesso mínimo a essas tecnologias, deveriam, além das disciplinas básicas essenciais, contar com atividades pedagógicas capazes de prepará-los para a construção do pensamento computacional.

Como o ensino remoto foi algo inesperado, professores que não estavam familiarizados com metodologias digitais, tais como web conferências e videoaulas, podem apresentar resistências para aceitarem a nova forma de ensinar e aprender devido a dificuldades vivenciadas. 
Compreender dificuldades e oportunidades envolvidas em um processo é relevante para refletir e fazer intervenções que busquem melhorias, seja no campo pedagógico ou no campo estrutural. Dessa forma, esta pesquisa visa coletar comentários de alunos e professores que estão vivenciando o ensino remoto buscando conhecer suas dificuldades, anseios e oportunidades percebidas.

\section{Metodologia da pesquisa}

A presente pesquisa traz a análise do ensino remoto e para isso realiza entrevistas semiestruturadas com pessoas envolvidas no processo de ensino de aprendizagem desta modalidade de ensino. Para Vieira (2017), a técnica da entrevista semiestruturada é conhecida como um dos principais meios para a coleta de dados na pesquisa qualitativa. Para o autor, esta técnica se caracteriza por perguntas estabelecidas num roteiro flexível em torno de um assunto do interesse de uma pesquisa para elucidação do seu objeto.

Este tipo de pesquisa por entrevista é encontrado em alguns trabalhos e pode-se citar Silva et al (2017), ao analisar as concepções de sustentabilidade de professoras do ensino fundamental I e Masetto, Nonato e Medeiros (2017) ao analisarem conceitos e elementos que vêm se consolidando a partir das pesquisas que vêm sendo desenvolvidas no âmbito do grupo de pesquisa Formação de Professores e Paradigmas Curriculares.

Os sujeitos participantes da entrevista foram alunos de professores de cursos de graduação e pós-graduação, bem como professores que atuem no ensino básico e superior. A Tabela 1 mostra o curso dos alunos entrevistados.

Tabela 1: Curos dos alunos entrevistados.

\begin{tabular}{|c|l|}
\hline Aluno & \multicolumn{1}{|c|}{ Curso } \\
\hline A1 & Mestrado em Ensino \\
\hline A2 & $\begin{array}{l}\text { Mestrado em Ensino e Graduação em Engenharia de } \\
\text { Computação }\end{array}$ \\
\hline A3 & Graduação em Engenharia Eétrica \\
\hline A4 & Mestrado em Ensino \\
\hline A5 & Graduação em Engenharia Eétrica \\
\hline A6 & Graduação em Engenharia Civil \\
\hline A7 & Graduação em Ciência e Tecnologia \\
\hline A8 & Mestrado em ensino \\
\hline A9 & Graduação em Ciência e Tecnologia \\
\hline A10 & Graduação em Engenharia Mecância \\
\hline
\end{tabular}

Como pode-se ver pela Tabela 1, dos alunos entrevistados, um deles é mestrando e graduando, três são mestrandos e seis são graduandos de quatro cursos diferentes. Em relação aos professores, a Tabela 2 mostra a atuação, em que se pode ver são de quatro áreas distintas atuando em níveis diferentes. 
Tabela 2: Atuação dos professores entrevistados.

\begin{tabular}{|c|l|l|}
\hline Professor & \multicolumn{1}{|c|}{ Área } & \multicolumn{1}{|c|}{ Nível } \\
\hline P1 & Química & Graduação \\
\hline P2 & Matemática & Ensino médio \\
\hline P3 & Matemática & Graduação \\
\hline P4 & $\begin{array}{l}\text { Educação } \\
\text { financeira }\end{array}$ & $\begin{array}{l}\text { Ministrante de cursos e } \\
\text { palestras }\end{array}$ \\
\hline P5 & Português & Ensino médio \\
\hline P6 & Matemática & Graduação e Pós-graduação \\
\hline
\end{tabular}

Os entrevistados foram escolhidos de forma heterogênea para que se pudesse ter uma visão mais ampla das dificuldades e oportunidades vistas pelos alunos e professores em uma modalidade de ensino em que é nova para muitos.

\section{Resultados e discussão}

A entrevista contou com a participação de estudates e professores que estão atuando no ensino remoto na época de distanciamneto social. Aos entrevistados, foi pedido um relato a respeito de sua visão quanto às experiências e dificuldades vivenciadas nesta modalidade de ensino. No que segue, são apresentados os depoimentos dos estudantes que foram descritos na tabela 1.

Aluno A1: É uma realidade totalmente nova, que possui fatores positivos e negativos. Como estou em casa, não preciso me deslocar da cidade que resido para onde estudo. Possuo um local específico para estudos, com notebook e o smartphone. Se preciso falar com um professor, mando mensagens no WhatsApp ou e-maill. Como desvantagem, posso citar o acesso aos livros físicos da biblioteca e aos demais professores e colegas, bem como aulas que poderiam ser mais proveitosas na forma presencial. Destaco ainda a assuntos que seriam mais agil no ensino presencial e o acesso a internet que é nem sempre é boa.

Aluno A2: O ensino remoto, sobretudo no âmbito da educação pública, pode ser visto como uma ferramenta de igualdade social e da capacidade de adaptação do homem em situações adversas. É, para professores e alunos, sair da zona de conforto, mesmo com as dificuldades de infraestrutura e capacitação técnica específica pra tal contexto.

Aluno A3: O ensino por meio de plataformas digitais online se torna, de certa forma, restrito. Comparado ao ensino presencial o rendimento se torna menos produtivo, pois as dúvidas ficam com respostas vagas. Aulas assistidas como as do ensino remoto, na tela de um computador ou celular se torna cansativa, diminuindo o rendimento de aprendizagem. Por outro lado, proporciona oportunidades como não precisar se deslocar da sua casa, havendo necessidade apenas de internet.

Aluno A4: $\mathrm{O}$ ensino remoto proporcionou a continuidade das aulas que não puderam ocorrer presencialmente. Ao meu ver, não ocorreram prejuízos consideráveis na aprendizagem em comparação ao modelo presencial. Ademais, acredito que a 
interatividade restou preservada e favoreceu a aproximação com os recursos tecnológicos que são de fundamental importância para o crescimento estudantil e profissional em qualquer área.

Aluno A5: O ensino remota vem proporcionando novas opções de ensino como plataformas de video. Apesar disso o afastamento do professor e aluno por diversas vezes dificulta o aprendizado.

Aluno A6: Apesar de ser uma modalidade de ensino que tem avançado, e que permite uma maior flexibilidade com relação aos horários de estudos e a realização de atividades, uma vez que não se faz necessário comparecer as aulas, esse método não é eficaz, para o discente é bastante complicado se manter centrado tantas horas na tela, ocorre então a falta de estímulo. Sem falar na dificuldade de comunicação entre aluno e professor para tirar as dúvidas.

Aluno A7: Á frente dos transtornos vividos atualmente, ensino remoto busca amenizar, nesse período, os prejuízos que pode ocasionar tantos aos alunos de ensino fundamental, médio e superior. Um dos principais desafios enfrentados durante o ensino remoto, é as realidades diferentes em que um colégio de elite tem mais estratégias a disposição quando comparado a um colégio na zona rural.

Aluno A8: Apesar dos esforços para que as aulas remotas possam suprir as necessidades, acredito que ainda ficam carências com relação a interação, pois alguns sentem-se mais inibidos a participar e tirar dúvidas, além da questão da concentração que é afetada pelo ambiente em que está inserido.

Aluno A9: Mesmo com a tecnologia ao alcance de praticamente todos de uma nação, usar da mesma como único método possível de ensino devido as circunstâncias extraordinárias, mostra desafios e dificuldades de ensino e aprendizado, tanto na parte de orientação como do orientado. Mas, é uma grande oportunidade de aperfeiçoar-se, aprender e adaptar as circunstâncias.

Aluno A10: A experiencia do ensino a distancia vem sendo tranquila, umas vez que sempre priorizei o estudo dos conteudos das disciplinas sozinho em casa. Entretanto, a falta do ambiente da sala de aula e dos laboratorios está sendo um fator batamte negativo para a integração do conhecimento teórico aprendido na disciplina.

Os alunos apontam dificuldades como acesso à internet e livros físicos, capacidade técnica, falta de produtividade, estímulo e interatividade, bem como desigualdade de oportunidades. O item mais citado é a falta de interação que ocorreria se fosse presencial. Segundo estes alunos, esse fato prejudica rendimento e causa um maior cansaço devido o esforço em manter-se por horas na tela de um computador ou celular.

Diante dessa falta de interação, acredita-se que este problema possa ser amenizado se o professor utilizar recursos digitais variados, pois Porfírio et al (2018) afirmam que utilizando-se dos diversos tipos de ferramentas, é possível criar nos alunos um sentimento de acolhimento, transmitindo a sensação de proximidade entre todos os envolvidos.

Quanto às oportunidades, são apontados a mobilidade de casa a universidade, capacidade de aperfeiçoar-se, aprender e adaptar-se a situações adversas, favorecimento da aproximação com os recursos tecnológicos, novas opções de ensino como 
plataformas de video, flexibilidade com relação aos horários de estudos e a realização de atividades, bem como amenização de prejuízos causados devido ao distanciamento social.

Em relação aos professores, os mesmos foram instigados a fornecerem um relato sobre o ensino remoto. Abaixo, são vistos seus depoimentos.

Professor P1: Para mim, o ensino remoto chegou com algumas dificuldades: novas tecnologias que estou aprendendo por conta-própria; um ambiente de aprendizagem diferente; Gravar vídeos e depois editar é um desafio. É demorado, exige espontaneidade, preciso ensaiar para não errar muito e ter que gravar novamente; Precisa de um local silencioso, pois os vizinhos ouvem músicas altas na hora que estou gravando e o som é capturado nos vídeos; a interação com os discentes é superficial e não sei se eles estão assistindo a aula que está acontecendo no ambiente. Mesmo com as situações acima, estou vendo o ensino remoto como uma oportunidade de levar conhecimento não só aos discentes da instituição. Criei uma conta no YouTube onde estou compartilhando as aulas. Por enquanto, os vídeos são privados, mas penso em deixar público posteriormente. Estou melhorando um pouquinho a cada vídeo.

Professor P2: Tive que me adaptar a essa realidade do ensino remoto. Não é fácil planejar aulas online de videoconferência, demanda tempo e um bom acesso à internet. Além disso, muitos alunos não participam. Hoje percebo que estou trabalhando em dobro, antes não tratava de assuntos do trabalho nos finais de semana, atualmente, o sábado e o domingo se tornaram dias comuns, como qualquer outro. A cobrança da instituição quase triplicou, e a forma de avaliação se torna imprevisível. Me preocupo diariamente se meus alunos estão aprendendo, pois sem o contato presencial com eles, não tenho como saber através de mensagens suas aflições, dificuldades e medos. Meus alunos, muitos deles, não possuem acesso à internet em casa, e se deslocam para casa do vizinho ou de algum familiar, e outros, não conseguem acesso e estão sem contato com atividades e aulas desde o início do isolamento. Muitos discentes, assumiram responsabilidades em casa após o isolamento, às vezes, não possuem um local apropriado e silencioso para estudar e não tem a compreensão nem o apoio dos próprios pais. São situações que me fazem refletir se, de fato, o ensino remoto está suprindo as necessidades, mas ao meu ver, não está, não de todos.

Professor P3: Acredito que uma das maiores dificuldades do ensino remoto foi a urgência com que as instituições de ensino tiveram que ofertá-lo. Não houve (para a maioria) tempo hábil para capacitação dos professores. Além do acesso limitado à internet de parte dos estudantes. Apesar disso, essa "nova" forma de ensino acabaria por se tornar inevitável, dado o mundo cada vez mais tecnológico em que vivemos. Diversas ferramentas digitais passaram a ser conhecidas a partir da tentativa de contornar esse quadro que estamos vivenciando.

Professor P4: O ensino remoto se apresentou como um desafio, pois a lidar com os recursos tecnológicos representa para muitos profissionais um ambiente novo que como qualquer outro requer adaptação. Entretanto, proporcionou a aproximação com os recursos tecnológicos que também se mostram excelentes objetos de aprendizagem e consequentemente promovem a diminuição de resistências e motivação dos alunos.

Professor P5: Tem sido bem difícil realizar as aulas remotamente. Percebo que os alunos que já tinham um bom desempenho estão conseguindo se sair bem, mesmo que com prejuízos, mas os que já tinham dificuldades, estão sendo ainda mais prejudicados. 
Sem contar o fato de que nem todos os alunos tem acesso aos meios necessários para terem as aulas online.

Professor P6: O ensino remoto exige uma pré-disposição para ensinar e aprender. Para contribuir com a construção satisfatória do conhecimento através desta modadlidade, o professor precisa está disposto a se capacitar quanto a novas tecnologias e novas abordagens metoloógicas para promover uma aula que desperte motivação e concentração.

Os professores apontam como maiores dificuldades a preparação para às aulas que demandam mais tempo devido a gravação e edição de vídeo, bem como a falta de um ambiente apropriado para a realização da aula. É notório que planejar e ministrar as aulas no formato remoto requer uma capacidade técnica que não houve tempo hábil para isso e os professores acabam tendo que aprender novas ferramentas de ensino, novos ambientes e novas tecnologias ao passo que precisam executar de forma rápida esse aprendiazado para tentar enviar algo de qualidade para os alunos.

Estes professores mostram o receio em ter aulas em que o aluno não consiga a apropriação adequada de conhecimentos concordando com Pinheiro, Seruffo e Pires (2019, p. 261) ao afirmarem:

Frisa-se que o uso de um recurso educacional, por si só, não pode ser considerado o único fator de sucesso ou fracasso de uma atividade. Faz-se necessário que $\mathrm{o}$ recurso esteja alinhado a outros procedimentos e que a maioria deles apresente qualidade de elaboração e execução. [Pinheiro; Seruffo e Pires, 2019, p. 261]

Eles também enxergam os desafios para os discentes, lembrando que este estão com dificuldades de acesso e com rendimento questionável. Quanto às oportunidades, são levantadas as considerações sobre uma maior socialização do conhecimento, $\mathrm{o}$ conhecimento de novas ferramentas, aproximação com os recursos tecnológicos que se mostram excelentes objetos de aprendizagem e promovendo a diminuição de resistências, aumentando a motivação dos alunos. [Feitosa \& Lavor, 2020].

\section{Considerações finais}

Diante do esposto, pode-se ver que o ensino remoto é uma modalidade que está fazendo parte da vida da maioria dos envolvidos pela primeira vez. Muitos estão habituados a aulas com a interação entre professor e aluno, com acesso a bibliotecas físicas e experimentos laboratoriais. Essa prática foi rompida sem a escolha de professores e alunos, devido ao momento de distanciamento social vivido e o ensino remoto foi posto em ação com a finalidade substituir, ao menos em partes, o ensino presencial.

Os alunos entrevistados comentam sobre as facilidades e oportunidades oferecidas pelo novo formato, uma vez é possível reduzir locomoção para o ambiente de estudo e vivenciar novas maneiras de estudo, tendo acesso a novos materiais e conhecendo plataformas de simulações. Eles também destacam as dificuldades de adaptação ao novo ambiente, bem como problemas de conexão e em especial, a falta de interação que ocorreria se fosse em ensino presencial.

Os professores relatam a falta de tempo para a capacitação, comentando que há sobrecarda de trabalho até em finais de semana para poderem cumprir um planejamento adequado, além de demonstrarem uma preocupação em relação a avaliação que pode ser 
comprometida. As oportunidades apontadas por eles estão relacionadas aos novos conhecimentos e poder atingir mais pessoas que no ensino presencial.

Os fatos relatados pelos envolvidos mostram preocupação com o formato de ensino que pode ser a educação do futuro, mas também apontam para a um desejo de melhorias para que as tecnologias possam atender a todos. Dessa forma, espera-se que os dados aqui apresentados contribuem para uma reflexão quanto a oferta de mecanismos que auxiliem os envolvidos e desperte novos trabalhos que busquem compreender uma educação a distância sem distâncias.

\section{Referências}

Charnei, Margaret (2020). "Dificuldade de aprendizagem do cálculo de área de figuras planas retangulares: uma possibilidade através do GeoGebra”, In: VIII Congresso Brasileiro de Informática na Educação (CBIE 2019), Brasília, 2020. https://br-ie.org/pub/index.php/wcbie/article/view/9008/6554, Maio.

Feitosa, Murilo Carvalho; Lavor, Otávio Paulino (2020). Ensino de circuitos elétricos com auxílio de um simulador do PhET. REAMEC - Rede Amazônica de Educação em Ciências e Matemática, v. 8, n. 1, p.126-139.

http://periodicoscientificos.ufmt.br/ojs/index.php/reamec/article/view/9014/pdf. Maio.

Hitzschky, Rayssa Araújo; Arruda, Juliana Silva; Siqueira, Liliane Maria Ramalho de Castro, Castro Filho, José Aires de (2019). "A utilização de Recursos Educacionais Digitais (RED) de Língua Portuguesa no Ensino Fundamental e a formação docente: a inserção de RED em sala de aula". Revista Tecnologias na Educação, v. 31, p. 116.

https://tecedu.pro.br/wp-content/uploads/2019/12/Art11-Ano-11-vol31-Dezembro2019.pdf, Junho.

Masetto, Marcos Tarciso; Nonato, Bréscia; Medeiros, Zulmira (2017). "Inovação curricular no ensino superior: entrevista com Marcos Tarciso Masetto". Revista Docência do Ensino Superior, v. 7, n. 1, p. 203-210.

https://periodicos.ufmg.br/index.php/rdes/article/view/2300/1431. Junho

Melo, Elvis Medeiros de; Maia, Dennys Leite (2019). “Uma Análise Exploratória de Dados sobre o Uso do Smartphone por Estudantes de PósGraduação em Tecnologias Educacionais", Revista Tecnologias na Educação, v. 31, p. 1-20. https://tecedu.pro.br/wp-content/uploads/2019/12/Art2-Ano-11-vol31-Dezembro2019.pdf, Maio.

Mourão, Letícia dos Santos; Araújo, Lorena Cavalcante; Silva, Marcelo Pereira da (2019). "Educação virtual e marketing digital: uma análise do perfil "Efeito Orna" no Instagram”. Revista Tecnologias na Educação, v. 30, p. 1-13. https://tecedu.pro.br/wp-content/uploads/2019/12/Art1-Ano-11-vol30-Novembro2019.pdf. Junho.

Pimentel, Lucas; Nicolau, Marcos (2018). "Os Jogos de Tabuleiro e a Construção do Pensamento Computacional em Sala de Aula", In: Anais do III Congresso sobre Tecnologias na Educação (Ctrl+E 2018), Fortaleza. http://ceur-ws.org/Vol-2185/CtrlE_2018_paper_11.pdf, Maio. 
Pinheiro, Paulo Sérgio Brito; Seruffo, Marcos César da Rocha; Pires, Yomara Pinheiro (2019). "Experiência de Uso de um Aplicativo Educacional Para Dispositivos Móveis no Município de Castanhal - Pará", Revista Brasileira de Informática na Educação - RBIE, v. 27, n. 3, p. 242-264. https://www.br-ie.org/pub/index.php/rbie/article/view/v27n03242264/6690, Maio.

Porfírio, Camila Tauane; Sobreira Júnior, Otávio Vieira; Pantoja, Lydia D. Maia; Paixão, Germana Costa (2018). "Atividades Assíncronas em Um Curso de Graduação a Distância: Aceitação, Participação e Desempenho dos Discentes”, In: Anais do III Congresso sobre Tecnologias na Educação (Ctrl+E 2018), Fortaleza. http://ceur-ws.org/Vol-2185/CtrlE_2018_paper_39.pdf, Junho.

Rodrigues Júnior, José Florêncio; Véras, Sonia Carvalho Leme Moura (2019). “A Comunicação, a Colaboração e o Diálogo pela Web: uma Evidência”, In: Anais do IV Congresso sobre Tecnologias na Educação (Ctrl+E 2018), Recife. https://sol.sbc.org.br/index.php/ctrle/article/view/8885/8786, Junho.

Silva, Arthur William Pereira da; Coelho, Ana Lúcia de Araújo Lima; Santos, Helaine Cristine Carneiro; Oliveira, Brenda Nathalia Fernandes (2017). "Entrevista com Professoras do Ensino Fundamental I sobre Educação para a Sustentabilidade". Revista Lumen, v. 4, n.2, p. 1-9. Junho.

Vieira, Francisco Giovanni David (2017). "Ensino de Marketing por meio de entrevista semi-estruturada". Revista Espaço Acadêmico, v. 17, n. 195, p. 1-8. http://periodicos.uem.br/ojs/index.php/EspacoAcademico/article/view/34940, Junho 